Wilson's disease. Detection of WD in children and young adults remains very difficult. The most important investigation is liver biopsy with the assessment of liver copper. Genetic analysis may help in doubtful cases.

\section{DNA DAMAGE AND APOPTOSIS EVALUATION IN LEUKOCYTES OF ICTERIC NEWBORNS AFTER PHOTOTHERAPY TREATMENT BY USING OF THE NEUTRAL COMET ASSAY}

doi:10.1136/archdischild-2012-302724.0728

'M Shahidi, ${ }^{2}$ SA Mesbah-Namin, ${ }^{3}$ S Heidari. 'Department of Biochemistry and Biophysics Mazandaran University of Medical Sciences, Sari; '2Department of Biochemistry, Tarbiat Modarres University, Tehran; ${ }^{3}$ MSC, Molecular Genetics, Saint Mary Fertility Center, Sari, Iran

Background and Aims Phototherapy is the most common form of treatment for jaundice. one of the various endpoints that can be used to investigate the potential of blood as a predictor of radiosensitivity is DNA damage and apoptosis. The aim of this study was to investigate the possible relation between phototherapy and DNA damage and apoptosis, in neonates with hyperbilirubinemia.

Methods The study included 15 healthy full-term newborns as control. The phototherapy group consisted of 30 non-physiologic jaundice that after 16 hours phototherapy, $1 \mathrm{ml}$ peripheral venous blood were obtained of them.

Results DNA damage immediately after phototherapy termination (IPT) was higher in jaundice infants than control one $(p<0.01)$. After 24 hours cells repaired their damages, as there wasn't any difference between these groups about this value. DNA damage in the phototherapy group was higher at IPT than 24 hours after that, but in the control one there weren't any differences between them(respectively $\mathrm{p}<0.001, \mathrm{p}>0.05$ ). Apoptosis value at 24 hours after phototherapy termination was higher than the IPT in the phototherapy group and was statistically significant $(\mathrm{P}<0.001)$.

Conclusions Since repair proofreading and fidelity properties isn't absolutely, then always this is probable that errors maybe occur during extensive DNA damages repair and finally these errors can cause mutation in DNA. If this event be in important and sensitive region of genome, harmful effects would menace phototherapytreated infants' later-life. So this is necessary to investigation of long-term genotoxic effects of phototherapy in phototherapytreated neonates.

\section{INTERLEUKIN-13 RECEPTOR A, GENE POLYMORPHISM AND IL-13 BLOOD LEVEL IN ATOPIC AND NON ATOPIC ASTHMATIC AND ALLERGIC RHINITIS CHILDREN}

doi:10.1136/archdischild-2012-302724.0729

YM Hussein. Medical Laboratories Department, College of Applied Medical Sciences, Taif University, Taif, Saudi Arabia

Objectives To assess the value of serum interleukin (IL) 13 levels as an immunological marker in atopic upper respiratory diseases, to clarify its differences in atopic and non atopic bronchial asthma and to determine the role of an IL-13 R $\alpha$ gene single nucleotide polymorphism (SNP) (A1398G) in the pathogenesis of these diseases.

Methods Seventy-five patients were compared with 25 agematched healthy volunteers. Serum total immunoglobulin (Ig) E and IL-13 levels were measured by enzyme-linked immunosorbent assay and the $I L-13 \mathrm{R} \alpha_{1}$ gene (A1398 G) was screened by specific polymerase chain reaction.

Results There was a non significant association between $G$ allele frequencies of the IL-13 $R \alpha_{1}$ (1398) gene polymorphism as compared to in controls. There were a significant increase in the serum level of total IgE \& IL-13 towards heterozygous AG and homozygous GG than homozygous AA in atopic asthma, non atopic asthma, and allergic rhinitis patients. There was a significant increase in the serum level of total IgE \& IL-13 towards homozygous GG than heterozygous AG in atopic asthma non atopic asthma, and allergic rhinitis patients for IgE and in all groups for IL-13.

Conclusion interleukin-13 receptor $\alpha 1$ subunit gene A1398G polymorphism does not contribute to asthma or allergic rhinitis susceptibility, although the interleukin-13 receptor $\alpha 1$ subunit gene locus might be involved in the control of immunoglobulin E production, IL13 can used as an immunological marker in atopic upper respiratory diseases and to differentiate between atopic and non atopic bronchial asthma.

\section{BRAIN GENOMIC RESPONSE AFTER PERINATAL ASPHYXIA AND FETAL ASPHYCTIC PRECONDITIONING}

doi:10.1136/archdischild-2012-302724.0730

${ }^{1,2}{ }^{2} \mathrm{~K}$ Cox, ${ }^{3} \mathrm{H}$ Vles, ${ }^{2} \mathrm{~L}$ Zimmermann, ${ }^{2} \mathrm{D}$ Gavilanes. 'S $S$ hool for Mental Health and Neuroscience, Maastricht University; ${ }^{2}$ Department of Paediatrics; ${ }^{3}$ Department of Paediatric Neurology, Maastricht University Medical Center, Maastricht, The Netherlands

Background and Aims Fetal asphyctic (FA) preconditioning has been shown to be effective in attenuating brain damage incurred by a subsequent perinatal asphyctic event. Unraveling mechanisms of this endogenous neuroprotection, is an important step towards new clinical strategies for asphyctic neonates. Genomic reprogramming is, at least in part, responsible for the protective effect of preconditioning in the brain. Therefore we investigated differential gene expression with whole genome micro-array.

Methods FA preconditioning was induced on E17 by reversibly clamping the uterine circulation for $30 \mathrm{~min}$. Perinatal asphyxia (PA) was induced at E21/22 by submersing the uterine horns including pups in a water bath for 19 minutes. Four experimental groups were sacrificed 6 and $96 \mathrm{~h}$ after birth: Control, FA, PA, and preconditioned animals that underwent perinatal asphyxia (FAPA). Whole genome transcription was investigated with the Affymetrix Gene1.0ST chip and analyzed with the Bioconductor Limma package.

Results Figure 1 and 2 depict the number of differentially regulated transcripts respectively 6 and 96 hours after birth.

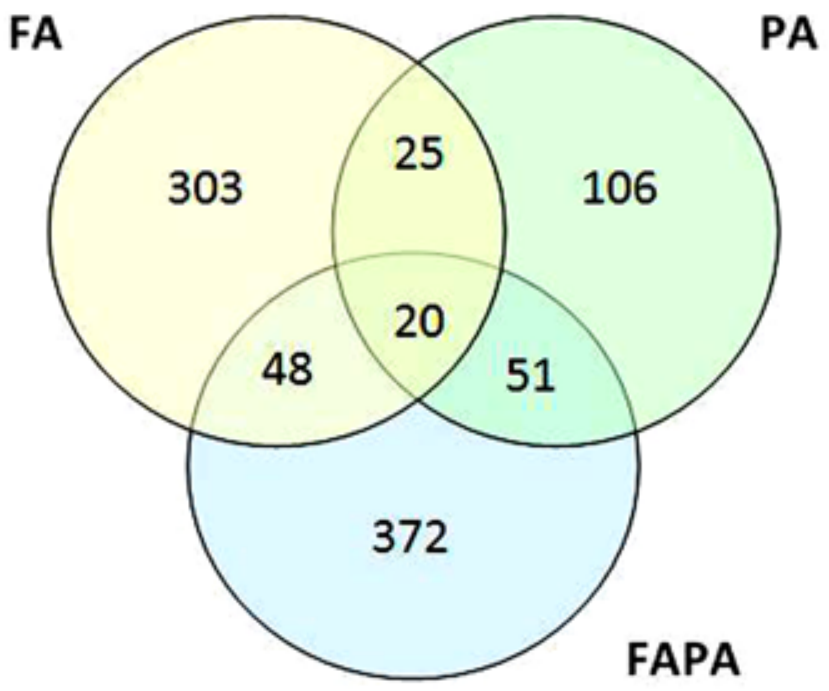

Abstract 730 Figure 1 Number of differentially expressed transcripts compared to control $(p<0.01)$, 6 h after birth 